Article

\title{
Indoor and Outdoor Exposure to Volatile Organic Compounds and Health Risk Assessment in Residents Living near an Optoelectronics Industrial Park
}

\author{
Ta-Yuan Chang ${ }^{1, * \mathbb{C}}$, Chin-Lin Liu ${ }^{1}$, Kuei-Hung Huang ${ }^{1}$ and Hsien-Wen Kuo ${ }^{2} \mathbb{C}$ \\ 1 Department of Occupational Safety and Health, College of Public Health, China Medical University, No. 91, \\ Hsueh-Shih Road, Taichung 40402, Taiwan \\ 2 Institute of Environmental and Occupational Health Sciences, School of Medicine, \\ National Yang-Ming University, No.155, Sec.2, Linong Street, Taipei 11221, Taiwan \\ * Correspondence: tychang@mail.cmu.edu.tw; Tel.: +86-4-2205-3366 ext. 6203. Fax: 86-4-2207-9225
}

Received: 30 May 2019; Accepted: 5 July 2019; Published: 8 July 2019

check for updates

\begin{abstract}
This study aimed to determine indoor and outdoor levels of volatile organic compounds (VOCs) and to assess potential risks among residents living in the vicinity of an optoelectronics industrial park in 2006-2007. We used steel canisters to collect 72 indoor samples and 80 outdoor samples over $24 \mathrm{~h}$. Gas chromatography with a mass-selective detector was used for qualitative and quantitative analyses. The amounts of time residents spent doing activities in different microenvironments were determined by the self-administered questionnaire. The chronic hazard index (HIc) and cancer risk were applied to assess the non-carcinogenic and carcinogenic risks of VOCs among residents. Four VOCs of ethanol (indoor: $77.8 \pm 92.8 \mu \mathrm{g} / \mathrm{m}^{3}$; outdoor: $26.8 \pm 49.6 \mu \mathrm{g} / \mathrm{m}^{3}$ ), toluene $\left(67.0 \pm 36.7 \mu \mathrm{g} / \mathrm{m}^{3} ; 56.9 \pm 19.0 \mu \mathrm{g} / \mathrm{m}^{3}\right), \mathrm{m} / \mathrm{p}$-xylene $\left(50.8 \pm 66.1 \mu \mathrm{g} / \mathrm{m}^{3} ; 21.2 \pm 20.3 \mu \mathrm{g} / \mathrm{m}^{3}\right)$, and acetone $\left(37.7 \pm 27.5 \mu \mathrm{g} / \mathrm{m}^{3} ; 25.8 \pm 9.8 \mu \mathrm{g} / \mathrm{m}^{3}\right)$ were identified as dominant components in both the indoor and outdoor environments. Total VOCs and six VOCs of benzene, toluene, ethylbenzene, $\mathrm{m} / \mathrm{p}$-xylene, o-xylene, and ethanol in indoor sites were significantly higher than those in outdoor sites (all $p$-values $<0.05$ ). All estimated HIc values were less than unity and the cancer risk of benzene exposure was $1.8 \times 10^{-4}$ (range: $9.3 \times 10^{-5}$ to $3.4 \times 10^{-4}$ ) based on resident time-weighted patterns. Strategies to reduce benzene exposure should be implemented to protect public health.
\end{abstract}

Keywords: exposure assessment; health risk assessment; indoor air; optoelectronics industrial park; volatile organic compounds

\section{Introduction}

In order to revitalize economic growth, increase employment, and promote the upgrade of traditional industries, many emerging industrial parks have been established to construct a comprehensive chain of products for efficiency in developing countries. Among them, the Central Taiwan Science Park (CTSP), which has been in operation since July 2003, was built in the middle of Taiwan mainly to produce the thin-film transistor liquid-crystal display (TFT-LCD). According to the latest official statistics, this park, with a total area of 1486 hectares, includes 196 companies, 9 incubation centers, and 6 research units to attract the planned investment of $\$ 697.3$ billion in capital and the creation of 49,023 jobs by the end of March 2019 [1].

Exposure to volatile organic compounds (VOCs) has been reported to be associated with adverse health effects, including acute and chronic respiratory diseases, eye and throat irritation, neurological toxicity, kidney dysfunction, and lung cancer [2-9]. As the distance between the CTSP and the nearby 
communities is short (less than $1 \mathrm{~km}$ ), the emission of VOCs from industrial operations, which increases residents' exposure to air toxins, is of great concern. A previous study demonstrated the association between optoelectronics industrial activities and the increasing concentration of VOCs in the CTSP [10]. The concentrations of a total sum of 14 VOCs, toluene, acetone, and ethanol, were significantly associated with the increment of optoelectronic sales per million U.S. dollars after adjusting for traffic and meteorological conditions [10]. In the TFT-LCD companies, the measured VOCs included ethanol, acetone, isopropyl alcohol (IPA), propylene glycol monomethyl ether acetate (PGMEA), propylene glycol monomethyl ether, cyclohexanone, benzene, toluene, m/p-xylene, o-xylene, butyl acetate, and hexane [4,11,12]. Additionally, a very common chemical compound, tetramethylammonium hydroxide (TMAH), was reported to be used in the anisotropic wet etching of the TFT-LCD manufacturing processes [13].

To the best of our knowledge, no studies have been conducted to evaluate the potential health risks due to VOC exposure among inhabitants living in the vicinity of an optoelectronics industrial park. The purpose of this study was to determine indoor and outdoor levels of VOCs and to assess health risks among residents living near the CTSP over two years.

\section{Materials and Methods}

\subsection{Study Site}

The main base of the CTSP is located on the border between Situn District and Daya District of Taichung City in the middle of Taiwan, as shown in Figure 1a. There are about 325,300 people living in these two districts around the CTSP. The climate of the CTSP is a typical subtropical climate. During the study period, the average temperature ranged from 25.0 to $26.6^{\circ} \mathrm{C}$, the average humidity ranged from $66 \%$ to $75 \%$, the average wind velocity ranged from 0.5 to $2.3 \mathrm{~m} / \mathrm{sec}$, and the prevailing wind was from the northwest direction (42\% of the time in spring and summer and $77 \%$ in autumn and winter).

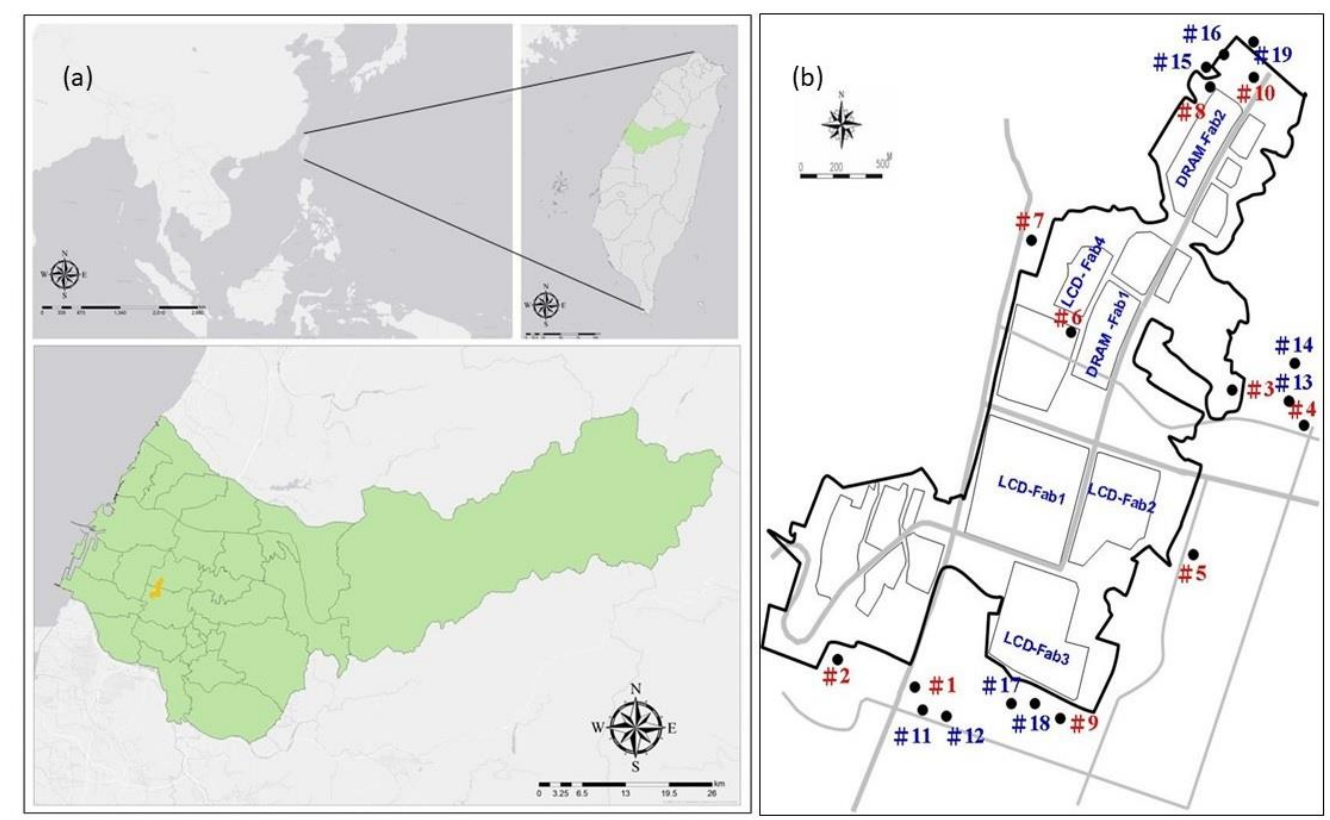

Figure 1. (a) Locations of the Central Taiwan Science Park (CTSP) in Taiwan; (b) outdoor (\#1-\#10, $\mathrm{n}=10$ ) and indoor (\#11-\#19, $\mathrm{n}=9$ ) sampling sites set up around the CTSP. DRAM-dynamic random access memory, LCD-liquid-crystal display.

\subsection{Indoor and Outdoor Sampling}

The sampling period was two years during 2006-2007. Each year covered four-day sampling to represent four seasons. Ten sampling sites were set up to collect ambient samples simultaneously from 
07:30 to 07:30 over $24 \mathrm{~h}$. As shown in Figure $1 \mathrm{~b}$, these outdoor sites included five sites located along four main roads to monitor both the traffic and industrial emissions of VOCs (i.e., \#1, \#4, \#5, \#7, and \#10), four sites close to adjacent residential communities within $1.2 \mathrm{~km}$ of the park (such as \#2, \#3, \#8, and \#9), and one site with the estimated maximum concentration by the Industrial Source Complex (ISC) Short-Term 3 model (i.e., \#6) to determine VOCs emitted mainly from industrial sources. Additionally, indoor samples were obtained from the living rooms of nine houses to estimate the inhalation exposure of residents to VOCs within $1.2 \mathrm{~km}$ of the park (i.e., \#11-\#19). The self-administrated questionnaire was also used to collect residents' daily time-activity patterns, lifestyle, and potential indoor sources of VOCs.

\subsection{VOC Concentration Analysis}

Integrated ambient air samples were collected in 6 L SUMMA stainless steel canisters with silonite-coated valves (29-10622G model, Entech Instruments Inc., Simi Valley, CA, USA). Flow rates of $4.2 \mathrm{~mL} / \mathrm{min}$ were used for 24-hour sampling. All canisters were cleaned using humid zero air with ten filling/evacuating cycles before sampling. One out of ten clean canisters was chosen to be analyzed to ensure that the concentration of all compounds inside a canister was below 10 parts per billion by volume (ppbv) and less than $0.2 \mathrm{ppbv}$ for each of targeted VOC. Otherwise, the re-cleaning processes were performed for all canisters. Sampling and analysis of the samples followed the U.S. Environmental Protection Agency Compendium Method TO-15 [14]. An injection volume of $100 \mathrm{~mL}$ for VOCs sampled in the canister was concentrated in an ENTECH 7100A cryogenic concentrator and was injected into a HP6890 gas chromatograph coupled to a HP5973 mass-selective detector (GC/MS). The ENTECH 7100A concentrator first transferred the air sample through a liquid nitrogen cooled cryogenic trap of glass beads at $-150{ }^{\circ} \mathrm{C}$ for the removal of water. The trapped VOCs were then transferred by pure helium to a secondary Tenax TA trap at $-30{ }^{\circ} \mathrm{C}$ for the removal of $\mathrm{CO}_{2}$. The secondary trap was heated $\left(180^{\circ} \mathrm{C}\right.$ for $\left.3.5 \mathrm{~min}\right)$ to transfer the target VOCs to a third cryogenic trap at $-160^{\circ} \mathrm{C}$. Finally, the trap was rapidly heated to $70^{\circ} \mathrm{C}$, and then the VOCs were transferred to the GC/MS system. A capillary column (J\&W DB-502.2, $60 \mathrm{~m} \times 0.25 \mathrm{~mm} \times 1.4 \mu \mathrm{m}$ ) was used in this system. The analysis started at $35^{\circ} \mathrm{C}$ and immediately increased at a rate of $5{ }^{\circ} \mathrm{C} / \mathrm{min}$ to $90^{\circ} \mathrm{C}$. The temperature was held at $90^{\circ} \mathrm{C}$ for 2 minutes and then raised to $170^{\circ} \mathrm{C}$ at a rate of $7{ }^{\circ} \mathrm{C} / \mathrm{min}$ and kept at $170^{\circ} \mathrm{C}$ for 3.3 minutes. Finally, the temperature was increased from $170^{\circ} \mathrm{C}$ to $210^{\circ} \mathrm{C}$ at a rate of $10^{\circ} \mathrm{C} / \mathrm{min}$ and held at $210^{\circ} \mathrm{C}$ for 5 minutes. The carrier gas was helium at a flow rate of $1 \mathrm{~mL} / \mathrm{min}$. The split flow was set to give a split of 1:10 to avoid the peak broadening and tailing phenomenon. The MS was used to identify and quantify the eluted species based on each compound's retention time and fragmentation pattern. The operational conditions of MS were set to range from 33 to $300 \mathrm{amu}$ with the electron multiplier at $1.1 \mathrm{kV}$. The scan interval was 0.5 seconds and the scan speed was 5 scans per second.

\subsection{Quality Assurance/Quality Control}

The laboratory and field blanks, parallel samples, and duplicate measurements of samples were subjected to quality assurance and quality control procedures. In the laboratory, a blank sample was randomly selected from ten canisters that had completed the cleaning procedure for analysis to ensure that the concentration of all compounds inside was below $10 \mathrm{ppbv}$ and less than $0.2 \mathrm{ppbv}$ of any targeted VOC. A field blank was analyzed on each sampling day. Parallel samples and duplicate measurements of samples were analyzed to test the precision of the sampling and analytical techniques, respectively. The mean relative standard deviations (R.S.D.) for all the compounds measured at the level of $10 \mathrm{ppbv}$ were less than $10 \%$. A new calibration curve was determined each time. The detection limit of each compound was calculated from the data of five replicate measurements of low concentration samples and observed from their standard deviation. The analyzed VOCs revealed the detection limits ranged from $0.4 \mu \mathrm{g} / \mathrm{m}^{3}$ (ethanol) to $0.9 \mu \mathrm{g} / \mathrm{m}^{3}$ (propylene glycol monomethyl ether acetate, PGMEA). Four internal standards (bromochloromethane, 1,4-difluorobenzene, chlorobenzene-d5, and 1-bromo-4-fluorobenzene) blended in for each injection aliquot were used in the calibration system to 
confirm the stability of MS and to ensure data quality. The recovery difference between the standard gas and each target VOC was required to be less than $30 \%$. The recovery rates of all VOCs analyzed ranged from $96.2 \%$ (acetone) to $101.1 \%$ (m/p-xylene).

\subsection{Risk Estimates}

Benchmark estimates of carcinogenic and noncarcinogenic risks for each VOC were taken directly from the California Environmental Protection Agency (Cal-EPA) [15,16]. The chronic reference exposure levels (REL) for airborne toxicants proposed by the Cal-EPA were used for comparison purposes [15]. The hazard index of chronic effects for the $i$ VOC $\left(H I c_{i}\right)$ was calculated as follows. We first calculated the indoor and outdoor time-weighted average concentration of the $i \mathrm{VOC}\left(\overline{C_{i}}\right)$ over the study period using the following equation (1):

$$
\overline{C_{i}}=\frac{\text { Indoor }_{c} \times \text { Time }_{\text {indoor }}+\text { Outdoor }_{c} \times \text { Time }_{\text {outdoor }}}{\text { Time }_{\text {total }}},
$$

where Indoor ${ }_{c}$ represents the two-year average concentration of nine indoor sites, Time indoor $_{\text {in }}$ the average daily period spent in the indoor environment from the two-year questionnaire survey, Outdoor represents the two-year average concentration of 10 outdoor sites, Time outdoor $_{\text {is }}$ the average daily period spent in the outdoor environment, and Time total is $24 \mathrm{~h}$. Second, the time-weighted average concentration of specific VOCs was divided by its respective chronic reference exposure level (RELc $c_{i}$ ). Finally, we summed the $\overline{C_{i}} /$ RELc $_{i}$ measurements of specific VOCs with the same adverse effects of target organs or systems to obtain HIc $j$ for the $j$ health effects, as shown in Equation (2). Only VOCs with RELc and measured levels above the limit of detection each season were used to calculate specific $\mathrm{HIc}_{j}$ values. Residents living in the vicinity of this park had potential chronic health risks if the calculated $H I c_{j}$ of the specific adverse effect was greater than 1.

$$
H I c_{j}=\frac{\overline{C_{1}}}{R E L c_{1}}+\frac{\overline{C_{2}}}{R E L c_{2}}+\ldots+\frac{\overline{C_{i}}}{R E L c_{i}}
$$

where $i$ represents one of six VOCs with measurable REL, and $j$ represents different health effects.

We assumed that each resident had a respiration rate of $20 \mathrm{~m}^{3}$ per day and exposure to VOCs for 24 hours per day, 7 days per week. The two-year average levels of VOCs were used for residents' chronic exposure and were assumed to be representative of long-term exposure over eight years [15].

For cancer risks, our first step was to use the International Agency for Research on Cancer (IARC) classification system to group the measured VOCs. Then, we used the unit risk values proposed by the Cal-EPA for respective VOCs in the IARC Group 1 (carcinogenic to humans) or Group 2A (probably carcinogenic to humans) to calculate the potential cancer risks [16]. Again, two-year time-weighted average concentrations of VOCs were used to calculate cancer risks in specific target organs for all residents throughout the CTSP. We estimated a person's lifetime exposure on the assumption that a resident weighing $70 \mathrm{~kg}$ with a respiration rate of $20 \mathrm{~m}^{3}$ per day lived on a sampling site for $24 \mathrm{~h}$ per day and 365 days per year for 70 years [16]. The lifetime cancer risk (LCR) for each VOC was calculated using Equation (3):

$$
L C R_{i}=U R_{i} \times \overline{C_{i}},
$$

where $L C R_{i}$ is the estimated risk from VOC $i$ exposure, $\overline{C_{i}}$ represents the two-year time-weighted average concentration of VOC $i\left(\mu \mathrm{g} / \mathrm{m}^{3}\right)$, and $U R_{i}$ is the unit cancer risk $\left(\left(\mu \mathrm{g} / \mathrm{m}^{3}\right)^{-1}\right)$ for a given VOC.

\subsection{Statistical Analysis}

The Shapiro-Wilk test was first used to evaluate the normality of VOC concentration distribution for different environments (indoor or outdoor), measured seasons (compared with the spring), and monitored periods (2006 or 2007). The t-test was applied to compare the difference in specific VOCs and total VOCs between the indoor and outdoor measurements due to the concentration distributed 
normally from the Shapiro-Wilk test (all $p$-values $>0.05$ ). The Wilcoxon rank-sum test was used to compare the seasonal difference in specific VOCs between 2006 and 2007. All the analyses were performed using the Statistical Analysis Software (SAS) standard package for Windows version 9.1 (SAS Institute Incorporation, Cary, NC, USA), and the significance level was set at 0.05.

\section{Results}

Table 1 shows the average concentrations of indoor and outdoor VOCs over two years. Ethanol (indoor: $77.8 \pm 92.8 \mu \mathrm{g} / \mathrm{m}^{3}$; outdoor: $\left.36.8 \pm 29.6 \mu \mathrm{g} / \mathrm{m}^{3}\right)$, toluene $\left(67.0 \pm 36.7 \mu \mathrm{g} / \mathrm{m}^{3} ; 56.9 \pm 19.0 \mu \mathrm{g} / \mathrm{m}^{3}\right)$, $\mathrm{m} / \mathrm{p}$-xylene $\left(50.8 \pm 66.1 \mu \mathrm{g} / \mathrm{m}^{3} ; 21.2 \pm 20.3 \mu \mathrm{g} / \mathrm{m}^{3}\right)$, and acetone $\left(37.7 \pm 27.5 \mu \mathrm{g} / \mathrm{m}^{3} ; 25.8 \pm 9.8 \mu \mathrm{g} / \mathrm{m}^{3}\right)$ were identified as four dominant components both in the indoor and outdoor environments. Most of these VOCs were associated with traffic emissions except ethanol, acetone, IPA, cyclohexanone, and PGMEA, which were mainly detected in the optoelectronics plants [4,11,12]. The target compounds on the TO-15 method included benzene, toluene, ethylbenzene, $\mathrm{m} / \mathrm{p}$-xylene, o-xylene, styrene, methyl ethyl ketone (MEK), and methyl tertiary-butyl ether (MTBE). However, other VOCs of ethanol, acetone, ethyl acetate, IPA, cyclohexanone, and PGMEA were reviewed from the GC/MS data to examine the presence of compounds in the emission inventory. The total VOCs and 6 of 14 VOCs measured in the indoor sties were significantly higher than those measured in the outdoor sites, including benzene, toluene, ethylbenzene, $\mathrm{m} / \mathrm{p}$-xylene, o-xylene, and ethanol (all $p$-values $<0.05$ ). For the other eight VOCs, including styrene, acetone, MEK, ethyl acetate, IPA, MTBE, cyclohexanone, and PGMEA, there were no statistically significant differences between indoor and outdoor concentrations.

Table 1. Average concentrations $\left(\mu \mathrm{g} / \mathrm{m}^{3}\right)$ of indoor and outdoor volatile organic compounds (VOCs) over two years.

\begin{tabular}{ccc}
\hline \multirow{2}{*}{ Chemicals } & 2006-2007 Outdoor & 2006-2007 Indoor \\
\cline { 2 - 3 } & (Mean \pm SD, N = 80) (Range) & (Mean \pm SD, N = 72) (Range) \\
\hline Benzene & $4.9 \pm 2.8(2.3-10.1)$ & $7.0 \pm 4.1^{*}(3.6-12.6)$ \\
Toluene & $56.9 \pm 19.0(20.2-177.2)$ & $67.0 \pm 36.7^{*}(26.4-148.4)$ \\
Ethylbenzene & $7.8 \pm 5.1(4.2-15.7)$ & $17.1 \pm 22.4^{*}(6.0-45.1)$ \\
m/p-Xylene & $21.2 \pm 20.3(13.5-51.2)$ & $50.8 \pm 66.1^{*}(16.1-138.5)$ \\
o-Xylene & $6.6 \pm 4.9(4.3-11.3)$ & $17.1 \pm 23.4^{*}(5.9-55.1)$ \\
Styrene & $1.7 \pm 1.3(0.4-2.7)$ & $2.5 \pm 1.6(0.7-6.0)$ \\
Acetone & $25.8 \pm 9.8(16.9-34.9)$ & $37.7 \pm 27.5(28.7-53.5)$ \\
Methyl ethyl ketone & $14.9 \pm 7.6(7.8-36.4)$ & $13.7 \pm 6.8(2.3-27.4)$ \\
Ethanol & $36.8 \pm 29.6(9.0-88.4)$ & $77.8 \pm 92.8^{*}(23.1-226.9)$ \\
Ethyl Acetate & $10.7 \pm 3.9(4.0-27.2)$ & $11.5 \pm 6.8(5.6-23.3)$ \\
Isopropyl alcohol & $6.4 \pm 3.1(1.7-25.6)$ & $5.2 \pm 6.2(2.8-12.6)$ \\
Others ${ }^{\text {a }}$ & $1.0 \pm 1.7(\mathrm{ND}-4.8)$ & $2.5 \pm 3.3(\mathrm{ND}-11.4)$ \\
Total & $213.6 \pm 117.3(148.6-465.7)$ & $397.6 \pm 303.2^{*}(189.1-591.5)$ \\
\hline
\end{tabular}

a Including methyl tertiary-butyl ether (MTBE), cyclohexanone, and propylene glycol monomethyl ether acetate (PGMEA); Significant difference $(p<0.05)$ for the t-test.

The seasonal variations of indoor VOC concentrations measured in 2006 and 2007 are shown in Table 2. Eight of fourteen VOCs measured in spring in 2007 were significantly higher than those measured in the same season in 2006, including benzene, toluene, ethylbenzene, m/p-xylene, o-xylene, MEK, ethyl acetate, and IPA (all $p$-values < 0.05). In contrast, MEK monitored in summer and styrene monitored in autumn in 2007 were both significantly lower than those monitored in summer and autumn in 2006, respectively (both $p$-values $<0.05$ ). 
Table 2. Seasonal variations of indoor VOC concentrations $\left(\mu \mathrm{g} / \mathrm{m}^{3}\right)$ in 2006 and 2007.

\begin{tabular}{|c|c|c|c|c|c|c|c|c|}
\hline \multirow{2}{*}{ Chemicals } & \multicolumn{2}{|c|}{ Spring } & \multicolumn{2}{|c|}{ Summer } & \multicolumn{2}{|c|}{ Autumn } & \multicolumn{2}{|c|}{ Winter } \\
\hline & $2006(N=9)$ & $2007(N=9)$ & $2006(N=9)$ & $2007(N=9)$ & $2006(\mathrm{~N}=9)$ & $2007(N=9)$ & $2006(N=9)$ & $2007(\mathrm{~N}=9)$ \\
\hline Benzene & $4.0 \pm 1.2$ & $12.6 \pm 4.9^{*}$ & $9.8 \pm 6.6$ & $7.9 \pm 4.3$ & $3.6 \pm 2.3$ & $5.7 \pm 3.8$ & $6.0 \pm 2.3$ & $6.3 \pm 7.0$ \\
\hline Toluene & $34.0 \pm 8.8$ & $148.4 \pm 48.8^{*}$ & $95.9 \pm 69.2$ & $73.9 \pm 16.9$ & $32.4 \pm 16.1$ & $38.2 \pm 20.6$ & $26.4 \pm 18.4$ & $86.7 \pm 94.4$ \\
\hline Ethylbenzene & $6.0 \pm 2.2$ & $29.0 \pm 26.7^{*}$ & $18.2 \pm 16.2$ & $10.1 \pm 4.8$ & $7.3 \pm 5.8$ & $14.1 \pm 24.2$ & $6.7 \pm 5.2$ & $45.1 \pm 94.2$ \\
\hline m/p-Xylene & $16.1 \pm 7.0$ & $75.8 \pm 71.2^{*}$ & $53.8 \pm 47.6$ & $34.0 \pm 16.3$ & $18.0 \pm 12.8$ & $50.0 \pm 86.4$ & $20.4 \pm 15.4$ & $139 \pm 272$ \\
\hline o-Xylene & $5.9 \pm 2.3$ & $15.5 \pm 6.5^{*}$ & $24.3 \pm 25.4$ & $12.7 \pm 7.0$ & $6.1 \pm 4.4$ & $7.9 \pm 11.5$ & $9.0 \pm 8.3$ & $55.1 \pm 121.6$ \\
\hline Styrene & $2.2 \pm 0.6$ & $2.5 \pm 0.8$ & $6.0 \pm 2.3$ & $3.6 \pm 4.0$ & $2.0 \pm 1.1$ & $0.7 \pm 1.0^{*}$ & $1.9 \pm 2.3$ & $0.9 \pm 1.0$ \\
\hline Acetone & $33.2 \pm 34.8$ & $28.7 \pm 3.2$ & $37.9 \pm 34.2$ & $43.9 \pm 22.0$ & $53.5 \pm 65.4$ & $34.2 \pm 10.0$ & $36.1 \pm 30.2$ & $34.1 \pm 19.9$ \\
\hline MEK & $10.6 \pm 1.7$ & $27.4 \pm 11.6^{*}$ & $15.1 \pm 7.4$ & $2.3 \pm 3.2^{*}$ & $12.1 \pm 2.2$ & $22.6 \pm 14.7$ & $7.3 \pm 4.1$ & $12.3 \pm 9.2$ \\
\hline Ethanol & $227 \pm 364$ & $94.9 \pm 84.9$ & $31.7 \pm 21.4$ & $73.1 \pm 73.3$ & $70.7 \pm 89.6$ & $53.1 \pm 52.9$ & $23.1 \pm 22.0$ & $49.2 \pm 34.7$ \\
\hline Ethyl Acetate & $8.4 \pm 6.6$ & $23.3 \pm 9.0^{*}$ & $12.4 \pm 11.6$ & $11.7 \pm 7.5$ & $8.4 \pm 5.3$ & $13.8 \pm 5.6$ & $5.6 \pm 1.8$ & $8.1 \pm 6.9$ \\
\hline $\begin{array}{l}\text { Isopropyl } \\
\text { alcohol }\end{array}$ & $2.9 \pm 2.2$ & $5.9 \pm 3.1^{*}$ & $2.8 \pm 1.1$ & $4.6 \pm 6.4$ & $4.9 \pm 3.3$ & $12.6 \pm 26.6$ & $3.3 \pm 1.9$ & $4.2 \pm 4.9$ \\
\hline Total & $465 \pm 350$ & $554 \pm 162$ & $397 \pm 289$ & $355 \pm 122$ & $244 \pm 95$ & $386 \pm 320$ & $189 \pm 84$ & $492 \pm 105$ \\
\hline
\end{tabular}

Table 3 presents the residents' time activities in the indoor and outdoor environments during 2006-2007. The survey revealed that participants spent a mean of $16.6 \mathrm{~h}(69.2 \%)$ at home (i.e., living room, bedroom, and kitchen) and $7.4 \mathrm{~h}(30.8 \%)$ in the outdoor environment (including the workplace, commuting, and in other outside areas). The average times spent in the indoor and outdoor environments during $24 \mathrm{~h}$ over two years were applied to estimate the chronic exposure to specific VOCs for the health risk assessment.

Table 3. Average periods spent by residents in different indoor and outdoor environments over two years.

\begin{tabular}{cccccc}
\hline \multirow{2}{*}{ Environments } & \multicolumn{5}{c}{ Hours (\%) } \\
\cline { 2 - 6 } & Spring & Summer & Autumn & Winter & Average \\
\hline Indoor & & & & & \\
Living room & $6.0(25)$ & $5.6(23.3)$ & $8.0(33.3)$ & $8.9(37.0)$ & $7.1(29.7)$ \\
Bedroom & $7.2(30)$ & $8.3(34.6)$ & $7.9(32.9)$ & $8.0(33.3)$ & $7.9(32.7)$ \\
Kitchen & $1.9(7.9)$ & $1.7(7.1)$ & $1.4(5.8)$ & $1.4(5.8)$ & $1.6(6.7)$ \\
Outdoor & & & & & \\
Workplace & $4.0(16.7)$ & $4.0(16.7)$ & $4.0(16.7)$ & $2.7(11.2)$ & $3.7(15.3)$ \\
Commute & $0.6(2.5)$ & $0.4(1.6)$ & $0.5(2.1)$ & $0.2(1.0)$ & $0.4(1.8)$ \\
Outside areas & $4.3(17.9)$ & $4.0(16.7)$ & $2.2(9.2)$ & $2.8(11.7)$ & $3.3(13.8)$ \\
Total & $24(100)$ & $24(100)$ & $24(100)$ & $24(100)$ & $24(100)$ \\
\hline
\end{tabular}

The estimated concentration and hazard index of chronic health effects (HIc) for residents exposed to six VOCs is shown in Table 4. Toluene was identified as the highest exposure among inhabitants living in the vicinity of the CTSP with a mean of 63.88 (range: $24.49-157.28) \mu \mathrm{g} / \mathrm{m}^{3}$. Accordingly, the HIc due to toluene exposure was calculated as 0.213 (range: $0.082-0.524$ ), which was associated with potential effects on development, nervous system, and alimentary system. While considering the additive effects of VOC exposure on the same target organ or system, the highest HIc was 0.397 (0.166-0.946) because of exposure to benzene, toluene, xylene, and styrene on the nervous system. However, either single or combined exposure of these six VOCs was estimated with the chronic non-carcinogenic risk less than unity.

Table 5 shows the potential cancer risk among residents living in the vicinity of the CTSP. Because only benzene was identified as a carcinogen on the hematopoietic system (i.e., leukemia) to humans (i.e., IARC group 1 ) and no other VOC was classified as group 1 or $2 \mathrm{~A}$ according to the IARC system, the exposure level of benzene was conservatively applied for cancer risk assessment. Inhabitants were exposed to the benzene concentration of 6.10 (range: 3.20-11.83) $\mu \mathrm{g} / \mathrm{m}^{3}$ during 2006-2007. The exposure data were further calculated with the lifetime cancer risk of $1.8 \times 10^{-4}$ (range: $9.3 \times 10^{-5}-3.4 \times 10^{-4}$ ), which was higher than the general acceptable level of $1.0 \times 10^{-6}$ for the public. 
Table 4. Estimated levels $\left(\mu \mathrm{g} / \mathrm{m}^{3}\right)$ and hazard index of chronic health effects (HIc) for residents exposed to six VOCs in the vicinity of an optoelectronics industrial park.

\begin{tabular}{|c|c|c|c|c|}
\hline \multirow{2}{*}{ Chemicals } & \multirow{2}{*}{$\begin{array}{l}\text { Chronic REL } \\
\qquad\left(\mu \mathrm{g} / \mathrm{m}^{3}\right)\end{array}$} & \multirow{2}{*}{$\begin{array}{c}\text { Estimated Levels } \\
\text { Mean (range) }\end{array}$} & \multirow{2}{*}{$\frac{\text { HIc }}{\text { Mean (range) }}$} & \multirow{2}{*}{ Target Organs or System } \\
\hline & & & & \\
\hline Benzene & 60 & $6.10(3.20-11.83)$ & $0.102(0.053-0.197)$ & $\begin{array}{c}\text { Hematopoietic system; } \\
\text { development; nervous system }\end{array}$ \\
\hline Toluene & 300 & $63.88(24.49-157.28)$ & $0.213(0.082-0.524)$ & $\begin{array}{l}\text { Development; nervous system; } \\
\text { alimentary system }\end{array}$ \\
\hline Ethylbenzene & 3000 & $14.23(5.45-36.04)$ & $0.005(0.002-0.012)$ & $\begin{array}{l}\text { Alimentary system (liver); } \\
\text { kidney; development }\end{array}$ \\
\hline Xylene & 700 & $55.54(20.71-153.18)$ & $0.079(0.030-0.219)$ & Nervous system; eye \\
\hline Styrene & 900 & $2.25(0.61-4.98)$ & $0.003(0.001-0.006)$ & Nervous system \\
\hline \multirow[t]{2}{*}{ Isopropyl alcohol } & 7000 & $5.57(2.46-16.61)$ & $\begin{array}{c}0.001 \\
(<0.001-0.002)\end{array}$ & Kidney \\
\hline & Benzene & & $0.102(0.053-0.197)$ & Hematopoietic system \\
\hline \multicolumn{3}{|c|}{ Benzene, toluene, xylene, and styrene } & $0.397(0.166-0.946)$ & Nervous system \\
\hline \multicolumn{3}{|c|}{ Toluene and ethylbenzene } & $0.218(0.084-0.536)$ & Alimentary system \\
\hline \multicolumn{3}{|c|}{ Benzene, toluene, and ethylbenzene } & $0.320(0.137-0.733)$ & Development \\
\hline \multicolumn{3}{|c|}{ Ethylbenzene and isopropyl alcohol } & $0.006(0.002-0.014)$ & Kidney \\
\hline \multicolumn{3}{|c|}{ Xylene } & $0.079(0.030-0.219)$ & Eye \\
\hline
\end{tabular}

REL, reference exposure level.

Table 5. Estimated levels $\left(\mu \mathrm{g} / \mathrm{m}^{3}\right)$ and potential cancer risk for residents exposed to benzene in the vicinity of an optoelectronics industrial park.

\begin{tabular}{|c|c|c|c|c|c|}
\hline \multirow{2}{*}{ Chemicals } & \multirow{2}{*}{$\begin{array}{l}\text { Unit Risk } \\
\left(\mu \mathrm{g} / \mathrm{m}^{3}\right)^{-1}\end{array}$} & \multirow{2}{*}{ IARC Group } & Estimated Levels & Cancer Risk & \multirow{2}{*}{$\begin{array}{c}\text { Target Organs } \\
\text { or System } \\
\text { (Tumor Type) }\end{array}$} \\
\hline & & & Mean (range) & Mean (range) & \\
\hline Benzene & $2.9 \times 10^{-5}$ & 1 & $6.10(3.20-11.83)$ & $\begin{array}{c}1.8 \times 10^{-4}(9.3 \\
\times 10^{-5}-3.4 \times \\
\left.10^{-4}\right)\end{array}$ & $\begin{array}{c}\text { Hematopoietic } \\
\text { system } \\
\text { (leukemia) }\end{array}$ \\
\hline
\end{tabular}

IARC, International Agency for Research on Cancer.

\section{Discussion}

\subsection{Indoor and Outdoor Exposure Assessment}

We found that the four VOCs of ethanol, toluene, $\mathrm{m} / \mathrm{p}$-xylene, and acetone were dominant components in the indoor and outdoor environments for residents living near this optoelectronics industrial park. These VOCs were also identified as the major compounds reported in the ambient outdoor environment during 2005 [10], but were different from those of IPA, acetone, benzene, toluene, and PGMEA observed in a semiconductor industrial park [17] or those of ethylene, MEK, N, $\mathrm{N}$-dimethylformamide, acrylonitrile, and toluene determined in a petrochemical industrial park [18]. The priority of indoor VOC levels was ethanol, toluene, $\mathrm{m} / \mathrm{p}$-xylene, and acetone, but the rank of outdoor ones changed to toluene, ethanol, acetone, and $\mathrm{m} / \mathrm{p}$-xylene in the present study. Ethanol and acetone were reported as the major compounds measured in a TFT-LCD company [4], and the toluene and $\mathrm{m} / \mathrm{p}$-xylene may be from the sources of traffic and industrial activities $[10,19]$.

Benzene, toluene, ethylbenzene, and xylene (i.e., $\mathrm{m} / \mathrm{p}$-xylene and o-xylene) are most common compounds of VOCs emitted from traffic [19], but partial levels may be released from the TFT-LCD manufacturing processes in this park. One previous study reported the detected level of benzene in the development, etching, photoresist stripping, rubbing and polyimide printing, spacer sealant, and hot press and cell attachment [11]. Both toluene and xylene were detected in the workplace of TFT-LCD companies $[4,11]$. Ethylbenzene was not identified in previous studies. In comparison with the major VOCs of ethanol and acetone measured in the manufacturing processes, the concentration ratio ranged from $0.4 \%$ (toluene/ethanol) [4] to $5 \%$ (toluene/acetone) [11].

We did not detect TMAH in either indoor or outdoor environments. TMAH is a widely utilized etchant in the optoelectronic manufacturing processes [13]. Dermal exposure to TMAH may result in 
alkalinity-related chemical burns, respiratory failure, and/or sudden death in humans [20,21]. Because of its ionic nature and low volatility, it is almost impossible to detect TMAH in ambient air.

In addition, the measured indoor levels of VOCs were obviously higher than those measured in the outdoor environment. These results were consistent with findings reported in previous studies [22,23]. Our questionnaire survey found that $39 \%$ of participants burned incense at home, $22 \%$ of inhabitants used fragrance inside, and $8 \%$ of residents had painted within the last one month. This indicated possible VOC sources emitted from the indoor environment. As only $17 \%$ of participants admitted using air conditioners during the sampling period, the indoor levels of VOCs were partially contributed to the outdoor sources in this study.

We also observed the highest concentration of indoor total VOCs in spring compared with those measured in other seasons in both $2006\left(465 \pm 350 \mu \mathrm{g} / \mathrm{m}^{3}\right)$ and $2007\left(554 \pm 162 \mu \mathrm{g} / \mathrm{m}^{3}\right)$. This is because $97 \%$ of subjects reported that they usually open windows for ventilation in the spring, which produces the highest indoor level of total VOCs in the present study.

\subsection{Health Risk Assessment}

We did not observe any chronic hazard indices of single or mixed VOCs greater than unity, which implied that no non-carcinogenic health effects were expected. The same results were reported in people living in the vicinity of the largest chemical production site in the Mediterranean area [24] and among workers in the rubber footwear industries in China [25]. In contrast, one previous study in southern Taiwan estimated the excess non-cancer risk among petrochemical workers as a result of exposure to acrylonitrile (respiratory system), 1,3-butadiene (reproductive system), hydrogen cyanide (nervous system, endocrine system, and cardiovascular system), and n,n-dimethylformamide (alimentary system and respiratory system) [18]. These differences revealed the variations in emitted sources and concentrations of VOCs between different industrial areas.

We observed a cancer risk due to benzene of greater than the acceptable level of $10^{-6}$ for lifetime exposure. The mean cancer risk of $1.8 \times 10^{-4}$ higher than $1.0 \times 10^{-4}$ was categorized as a definite risk [26]. The results were similar to other findings in different industrial areas, including oil-burning power and steel plants in Japan [23], the petrochemical complex in southern Taiwan [18], the largest chemical site in southern Europe and the Mediterranean region [24], and the rubber footwear industries in China [25]. All of these studies identified benzene exposure to be one of the highest cancer risks for workers and residents living in the vicinity of the industry. We recommend long-term monitoring of benzene levels and actions taken to reduce the emitted sources for public health.

This study presented the preliminary results conducted in 2006-2007 for residents living in the vicinity of the optoelectronics industrial park. The two-year average levels of indoor and outdoor VOCs, as well as the survey of residents' time activities, were used to estimate the potential non-carcinogenic and carcinogenic risks for inhabitants. On the basis of these findings, a follow-up survey was performed in 2019 to measure the indoor and outdoor levels of VOCs. We will share the comparison of results between 2006 and 2019 with readers in the future.

\subsection{Strengths and Limitations}

This study had the strength of combining the indoor and outdoor measurements of VOCs with time-activity patterns over two years for residents living near this optoelectronics park. Such detailed exposure data provided more precise estimations of potential non-carcinogenic and carcinogenic risks among inhabitants. However, some limitations still have to be mentioned. First, we only performed a 24-h sampling each season and used four-day results to present the annual levels. These results could not be completely representative for seasonal variations and could have been accidental. Greater frequencies of VOCs sampling (i.e., per week or per month) are preferable, but not practical. A fixed monitoring site of VOCs can overcome the limitation of inadequate sampling frequency, but no continuous monitoring stations have been set up around this park. Second, indoor sampling of VOCs in the living room instead of personal sampling restricted the investigation for exposure in different 
microenvironments (e.g., bedroom, kitchen, and study). This drawback may reduce the accuracy of the estimated exposure. Third, some standard deviations of indoor VOCs (such as ethylbenzene, $\mathrm{m} / \mathrm{p}$-xylene, o-xylene, ethanol, and IPA) exceeded the annual average levels, particularly in winter 2007 , indicating greater variations of indoor exposure in the microenvironment. Future studies have to extend the monitoring durations (i.e., one week or more in the house) to decrease the exposure variation. Fourth, a major limitation of this study is the lack of upwind monitoring and comparison of upwind and downwind data around the two clusters of sampling sites around this industrial park to determine the sources of VOCs. Fifth, traffic conditions around the sampling sites were not measured, even though the compounds of benzene, toluene, ethylbenzene, and xylene can be traffic-related. Sixth, the two-year monitoring mean, but not an eight-year (i.e., $12 \%$ of human lifetime) $[15,16]$ average was applied to estimate the chronic non-cancer and cancer risks. Because this optoelectronics park has been in operation for just over three years (since 2003), the emitted amount of VOCs may be less than that after a longer running period with growing production over time. This might underestimate the residents' chronic exposure. Finally, some default assumptions from risk assessment, such as $20 \mathrm{~m}^{3}$ inhaled air per day, daily exposure to VOC levels on 365 days per year, occupation of the current address over 70 years, and residents with the average weight of 70 kilograms, may generate uncertainty in cancer risk evaluation. A more detailed survey that includes this information can improve the accuracy of our estimated results.

\section{Conclusions}

This study revealed that residents living near this optoelectronics park had higher indoor exposure to VOCs than outdoor exposure, primarily from ethanol, toluene, $\mathrm{m} / \mathrm{p}$-xylene, and acetone. The estimated cancer risk for inhabitants was above the general acceptable level as a result of benzene exposure. Long-term monitoring of VOCs and reduction of benzene exposure in residents should be performed to monitor the human exposure to air toxins and ensure the protection of public health.

Author Contributions: Conceptualization, T.Y.C and H.W.K.; Methodology, T.Y.C., C.L.L., and K.H.H.; Software, C.L.L. and K.H.H.; Validation, T.Y.C. and H.W.K.; Formal Analysis, T.Y.C.; Investigation, C.L.L. and K.H.H.; Resources, T.Y.C.; Data Curation, T.Y.C.; Writing-Original Draft Preparation, T.Y.C., C.L.L., and K.H.H.; Writing-Review and Editing, H.W.K.; Supervision, H.W.K.; Project Administration, T.Y.C. and H.W.K.; Funding Acquisition, T.Y.C. and H.W.K.

Funding: This research was funded by the National Science Council, Taiwan, grant number NSC 95-EPA-Z-039-003 and China Medical University, grant number CMU96-130. The APC was funded by China Medical University, grant number CMU107-S-20.

Acknowledgments: We thank the National Science Council, Taiwan (NSC 95-EPA-Z-039-003) and China Medical University (CMU96-130, CMU107-S-20) for the financial support. We also want to thank Dr. Ruei-Hao Shie for his methodology consultation in the analyses of VOCs concentrations.

Conflicts of Interest: The authors declare no conflict of interest.

\section{References}

1. CTSP. About CTSP. Available online: https://www.ctsp.gov.tw/english/01about/abo_origins.aspx?v=20\&fr= 1142\&no=1143 (accessed on 22 May 2019).

2. Arif, A.A.; Shah, S.M. Association between personal exposure to volatile organic compounds and asthma among US adult population. Int. Arch. Occup. Environ. Health 2007, 80, 711-719. [CrossRef]

3. Boeglin, M.L.; Wessels, D.; Henshel, D. An investigation of the relationship between air emissions of volatile organic compounds and the incidence of cancer in Indiana counties. Environ Res 2006, 100, 242-254. [CrossRef] [PubMed]

4. Chang, T.Y.; Huang, K.H.; Liu, C.S.; Shie, R.H.; Chao, K.P.; Hsu, W.H.; Bao, B.Y. Exposure to volatile organic compounds and kidney dysfunction in thin film transistor liquid crystal display (TFT-LCD) workers. J. Hazard Mater. 2010, 178, 934-940. [CrossRef] [PubMed] 
5. Elliott, L.; Longnecker, M.P.; Kissling, G.E.; London, S.J. Volatile organic compounds and pulmonary function in the Third National Health and Nutrition Examination Survey, 1988-1994. Environ. Health Perspect. 2006, 114, 1210-1214. [CrossRef] [PubMed]

6. Rumchev, K.; Spickett, J.; Bulsara, M.; Phillips, M.; Stick, S. Association of domestic exposure to volatile organic compounds with asthma in young children. Thorax 2004, 59, 746-751. [CrossRef] [PubMed]

7. Ware, J.H.; Spengler, J.D.; Neas, L.M.; Samet, J.M.; Wagner, G.R.; Coultas, D.; Ozkaynak, H.; Schwab, M. Respiratory and irritant health effects of ambient volatile organic compounds. The Kanawha County Health Study. Am. J. Epidemiol. 1993, 137, 1287-1301. [CrossRef] [PubMed]

8. Wieslander, G.; Norback, D.; Bjornsson, E.; Janson, C.; Boman, G. Asthma and the indoor environment: the significance of emission of formaldehyde and volatile organic compounds from newly painted indoor surfaces. Int. Arch. Occup. Environ. Health 1997, 69, 115-124. [CrossRef]

9. Yorifuji, T.; Noguchi, M.; Tsuda, T.; Suzuki, E.; Takao, S.; Kashima, S.; Yanagisawa, Y. Does open-air exposure to volatile organic compounds near a plastic recycling factory cause health effects? J. Occup. Health 2012, 54, 79-87. [CrossRef]

10. Chang, T.Y.; Lin, S.J.; Shie, R.H.; Tsai, S.W.; Hsu, H.T.; Tsai, C.T.; Kuo, H.W.; Chiang, C.F.; Lai, J.S. Characterization of volatile organic compounds in the vicinity of an optoelectronics industrial park in Taiwan. J. Air Waste Manag. Assoc. 2010, 60, 55-62. [CrossRef]

11. Wu, C.H.; Feng, C.T.; Lo, Y.S.; Lin, T.Y.; Lo, J.G. Determination of volatile organic compounds in workplace air by multisorbent adsorption/thermal desorption-GC/MS. Chemosphere 2004, 56, 71-80. [CrossRef]

12. Lin, Y.C.; Chang, F.T. Optimizing operating parameters of a honeycomb zeolite rotor concentrator for processing TFT-LCD volatile organic compounds with competitive adsorption characteristics. J. Hazard Mater. 2009, 164, 517-526. [CrossRef] [PubMed]

13. Mori, I.C.; Arias-Barreiro, C.R.; Koutsaftis, A.; Ogo, A.; Kawano, T.; Yoshizuka, K.; Inayat-Hussain, S.H.; Aoyama, I. Toxicity of tetramethylammonium hydroxide to aquatic organisms and its synergistic action with potassium iodide. Chemosphere 2015, 120, 299-304. [CrossRef] [PubMed]

14. U.S. Environmental Protection Agency (USEPA). Compendium Method TO-15: Determination of Volatile Organic Omcpounds (VOCs) in Air Collected in Specially-Prepared Canisters and Analyzed by Gas Chromatography/Mass Spectrometry (GC/MS), Second ed.; U.S. Environmental Protection Agency: Cincinnati, OH, USA, 1999.

15. California Environmental Protection Agency. Air Toxics Hot Spots Program Risk Assessment Guidelines Part III: Technical Support Document for the Determination of Noncancer Chronic Reference Exposure Levels for Airborne Toxicants; California Environmental Protection Agency, Office of Environment Health Hazard Assessment: Oakland, CA, USA, 2000.

16. California Environmental Protection Agency (Cal EPA). Air Toxics Hot Spots Program Risk Assessment Guidelines Part II: Technical Support Document for Describing Available Cancer Potency Factors; California Environmental Protection Agency, Office of Environmental Health Hazard Assessment: Oakland, CA, USA, 2002.

17. Chiu, K.H.; Wu, B.Z.; Chang, C.C.; Sree, U.; Lo, J.G. Distribution of volatile organic compounds over a semiconductor Industrial Park in Taiwan. Environ. Sci. Technol. 2005, 39, 973-983. [CrossRef] [PubMed]

18. Chan, C.C.; Shie, R.H.; Chang, T.Y.; Tsai, D.H. Workers' exposures and potential health risks to air toxics in a petrochemical complex assessed by improved methodology. Int. Arch. Occup. Environ. Health 2006, 79, 135-142. [CrossRef] [PubMed]

19. Ho, K.F.; Lee, S.C.; Guo, H.; Tsai, W.Y. Seasonal and diurnal variations of volatile organic compounds (VOCs) in the atmosphere of Hong Kong. Sci. Total Environ. 2004, 322, 155-166. [CrossRef] [PubMed]

20. Wu, C.L.; Su, S.B.; Chen, J.L.; Lin, H.J.; Guo, H.R. Mortality from dermal exposure to tetramethylammonium hydroxide. J. Occup. Health 2008, 50, 99-102. [CrossRef]

21. Lin, C.C.; Yang, C.C.; Ger, J.; Deng, J.F.; Hung, D.Z. Tetramethylammonium hydroxide poisoning. Clin Toxicol (Phila) 2010, 48, 213-217. [CrossRef]

22. Jo, W.K.; Kim, K.Y.; Park, K.H.; Kim, Y.K.; Lee, H.W.; Park, J.K. Comparison of outdoor and indoor mobile source-related volatile organic compounds between low- and high-floor apartments. Environ. Res. 2003, 92, 166-171. [CrossRef]

23. Ohura, T.; Amagai, T.; Senga, Y.; Fusaya, M. Organic air pollutants inside and outside residences in Shimizu, Japan: levels, sources and risks. Sci. Total Environ. 2006, 366, 485-499. [CrossRef] 
24. Ramirez, N.; Cuadras, A.; Rovira, E.; Borrull, F.; Marce, R.M. Chronic risk assessment of exposure to volatile organic compounds in the atmosphere near the largest Mediterranean industrial site. Environ. Int. 2012, 39, 200-209. [CrossRef]

25. Li, Q.; Su, G.; Li, C.; Wang, M.; Tan, L.; Gao, L.; Mingge, W.; Wang, Q. Emission profiles, ozone formation potential and health-risk assessment of volatile organic compounds in rubber footwear industries in China. J. Hazard Mater. 2019, 375, 52-60. [CrossRef] [PubMed]

26. Sexton, K.; Linder, S.H.; Marko, D.; Bethel, H.; Lupo, P.J. Comparative assessment of air pollution-related health risks in Houston. Environ. Health Perspect. 2007, 115, 1388-1393. [CrossRef] [PubMed]

(C) 2019 by the authors. Licensee MDPI, Basel, Switzerland. This article is an open access article distributed under the terms and conditions of the Creative Commons Attribution (CC BY) license (http://creativecommons.org/licenses/by/4.0/). 